\title{
An analysis of the South African fruit logistics infrastructure
}

\author{
FE van Dyk* E Maspero ${ }^{\dagger}$ \\ Received: 1 July 2004; Revised: 8 October 2004; Accepted: 11 October 2004
}

\begin{abstract}
This paper gives an overview of a study that was done on the logistics infrastructure used by the South African fruit industry. Given the increasing production and export volumes, development of new markets and the shortage of logistics infrastructure capacity during peak seasons, the SA fruit industry identified the need to investigate the optimal usage of existing infrastructure on a national level and to make recommendations with regards to the development of additional infrastructure. Some background on the SA fresh fruit industry and its export supply chain are provided. This is followed by a description of the four project phases and their deliverables. The paper is concluded with the key findings of the study.
\end{abstract}

Key words: Logistics infrastructure, fresh fruit export.

\section{Introduction}

Towards the end of 2002 the Deciduous Fruit Producers' Trust initiated a national fruit logistics infrastructure study on behalf of a number of role-players in the fruit industry and its logistical chain.

The aim of the study was:

1. to promote effective and efficient logistics operations amongst all the role-players in the fresh fruit supply chain, and

2. to make recommendations for the utilisation of, and investment in, logistics infrastructure in order to

3. enhance the competitiveness of the SA fruit industry.

The study commenced on 1 April 2003 and was completed successfully on 31 March 2004. It was partially funded by the SA Department of Trade and Industry (DTI) through its

\footnotetext{
${ }^{*}$ Corresponding author: CSIR — Transportek, PO Box 320, Stellenbosch, 7599, email: fevandyk@csir.co.za

${ }^{\dagger}$ CSIR - Transportek, PO Box 320, Stellenbosch, 7599, South Africa
} 
Sector Partnership Fund. The study was conducted jointly by the CSIR, Optimal Agricultural Business Systems (OABS) and the University of Stellenbosch (US). From the US the following groups participated: the departments of Logistics, Agricultural Economics, Industrial Engineering and Applied Mathematics as well as the Executive Development group of the Business School. The CSIR acted as project manager.

This paper is organised as follows. In $\S 2$ some background on the SA fresh fruit industry is provided and $\S 3$ details the export supply chain. This is followed in $\S 4$ and 5 by a description of the four project phases and their deliverables. $\S 6$ details the key findings of the study. The paper closes, in $\S 7$, with a summary of the value of the study to the industry.

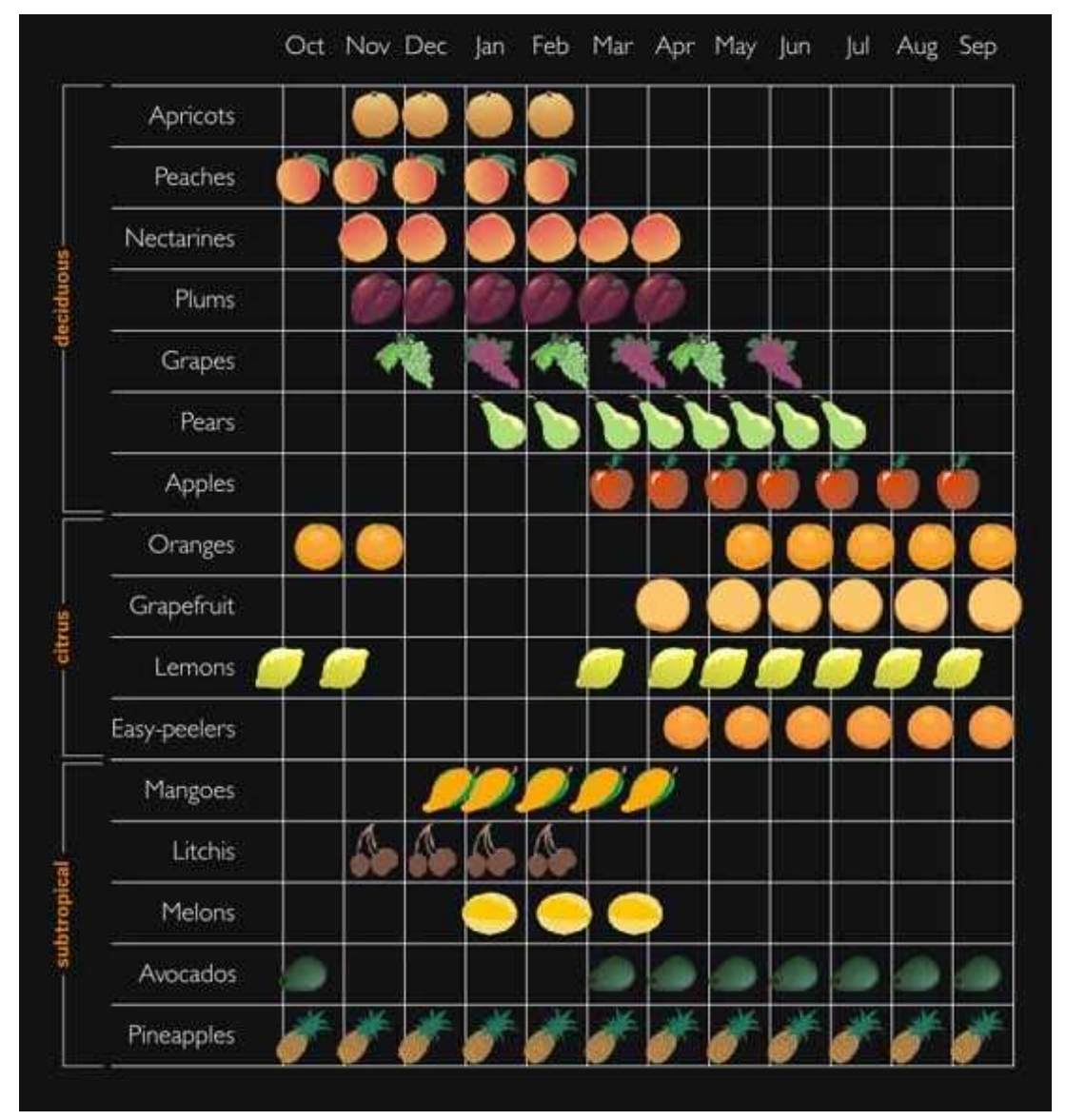

Figure 1: Calendar of fruit production in South Africa [8].

\section{Overview of the South African fresh ${ }^{1}$ fruit industry}

South Africa's climate and soil characteristics result in ideal conditions for many varieties of fruit to be grown; deciduous fruit, citrus and subtropical fruit are all grown throughout

\footnotetext{
${ }^{1}$ Fruit that is grown for fresh consumption (not grown for juicing, canning, pulping or any other specific processing/value adding industry).
} 
most of the country. Deciduous fruit includes table grapes (grapes grown for eating, not wine production), pome fruit (apples and pears), and stone fruit (apricots, peaches, nectarines and plums). The class citrus fruit is split into oranges, grapefruit, lemons, limes and soft citrus (also known as easy peelers, such as naartjies, mandarins, etc). Subtropicals are mangoes, litchis, melons, avocados and pineapples (while bananas also fall into this category, South Africa does not export any bananas).

Deciduous fruit is produced on a year round basis (see Figure 1 for a fruit calendar) and there are 75000 hectares of deciduous trees and vines planted in South Africa. In 2002, some 2,5 million metric tons of deciduous fruit was produced in South Africa. During the same time period, there were 2450 deciduous fruit farmers/producers employing 104440 people directly in the industry. These producers are coordinated and served by an umbrella organisation; the DFPT (Deciduous Fruit Producers Trust) which comprises the SA Apple and Pear Producers' Association (SAAPPA), SA Table Grapes (SAT), and SA Stone Fruit Producers' Association (SASPA) [8].

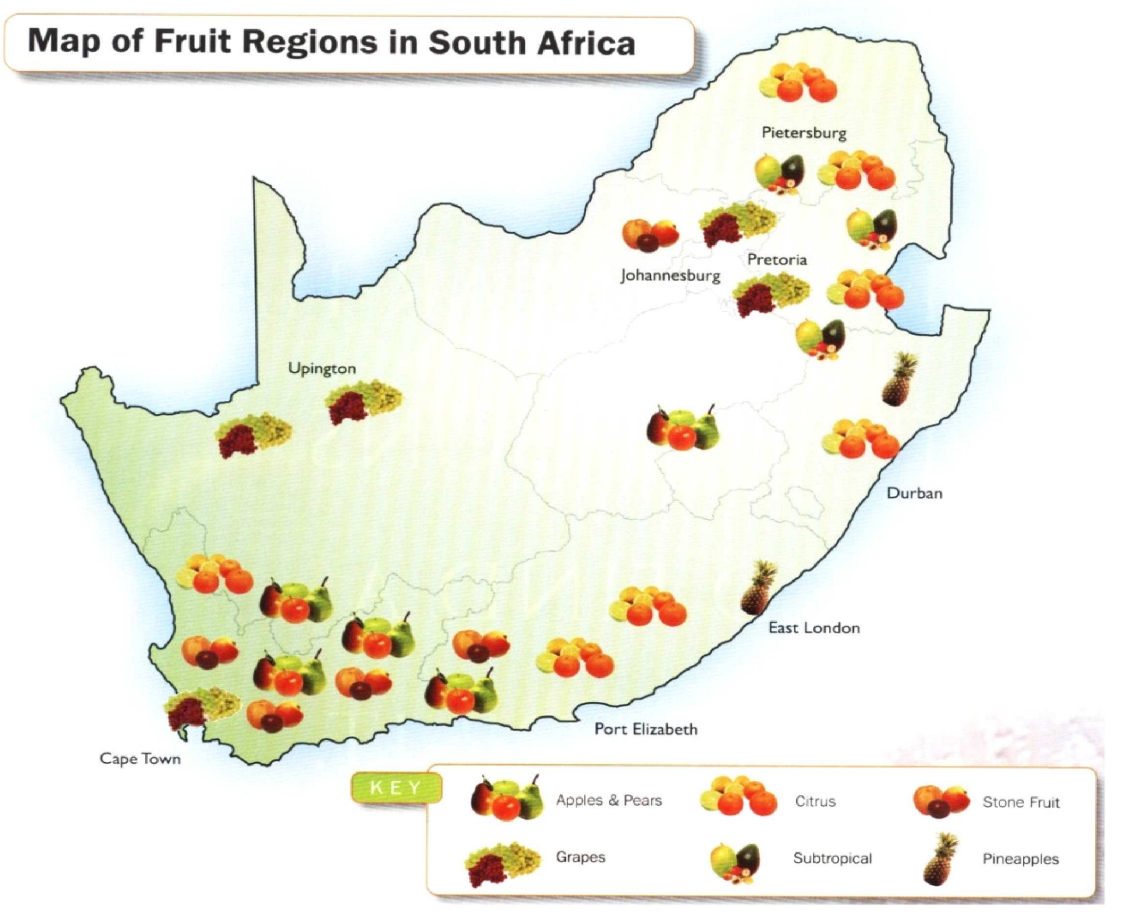

Figure 2: Fruit producing regions in South Africa [8].

Citrus fruit is produced in eight of the nine provinces (see Figure 2 for a map of South Africa indicating major production areas). There are currently 1073 citrus growers directly employing some 100000 people. It is estimated that during citrus season more than 1 million metric tons of citrus is exported (that excludes all the citrus produced for the local market!) [8].

Of all the agricultural industries in South Africa, the economic multiplier effect (forward 
and backward linkages) of the horticultural industry is the largest [7]. These include linkages to input supply industries and service providers as well as forward linkages to wholesalers, retailers, hawkers and many other role-players in the supply chain. In the Western Cape (the largest fruit producing province, where nearly $13 \%$ of the total formal sector jobs are in the agricultural sector) it was calculated that for each R1 million increase in the final demand for horticultural products 92.8 new job opportunities are created, whereas only 29.4 jobs are created in the non-agricultural sectors [7]. Also, for each R1 increase in final demand for horticultural products an additional R1,40 will be generated in the economy of the province and the government will receive R0,24 in revenue. Similar positive effects can be expected in the other provinces. (These calculations were based on a 1993 social accounting matrix.)

As South Africa produces more fruit than can be absorbed and consumed by the local market, and the fruit is of such high quality, a large percentage of fruit is exported. This export market is very important to the sustainability of the fruit industry as a whole. Fruit from South Africa is well received in the northern hemisphere due to the excellent quality and "opposite season." However, South Africa competes with other countries in the Southern Hemisphere such as Australia, Brazil, Chile, Argentina, etc. for market share in both the established markets of western Europe and the UK and the new/emerging markets such as the Middle and Far East [9].

South Africa's export regions are shown in Table 1 [9].

\begin{tabular}{ll}
\hline Region & \% \\
\hline Europe & $43 \%$ \\
UK & $25 \%$ \\
Middle East & $11 \%$ \\
Far East and Asia & $8 \%$ \\
Russian Federation & $7 \%$ \\
Americas & $3 \%$ \\
Africa & $2 \%$ \\
Indian Ocean Islands & $1 \%$ \\
\hline
\end{tabular}

Table 1: South Africa's export regions and percentages of total fruit exported to that region [9].

South African fruit is currently exported through the ports of Cape Town, Port Elizabeth, Durban and Maputo. Fruit is exported in cartons on pallets, either in refrigerated (reefer) containers (that are handled through the ports' container terminals) or in "bulk," i.e. the pallets are loaded into the hold of a specialised refrigerated vessel in conventional (fruit) terminals of ports. Almost no fruit is exported via air freight as it is too expensive. In addition to the container terminals, there are six dedicated fruit terminals (conventional terminals) in total at the four ports for loading specialised refrigerated vessels.

\section{$3 \quad$ Fresh fruit export supply chain}

The fresh produce export chain is complicated with time and temperature being key factors throughout the chain to ensure quality of produce and therefore the highest price 
obtainable on the international market. There are many role-players in the supply chain as can be seen in the simplified diagram of the chain in Figure 3.

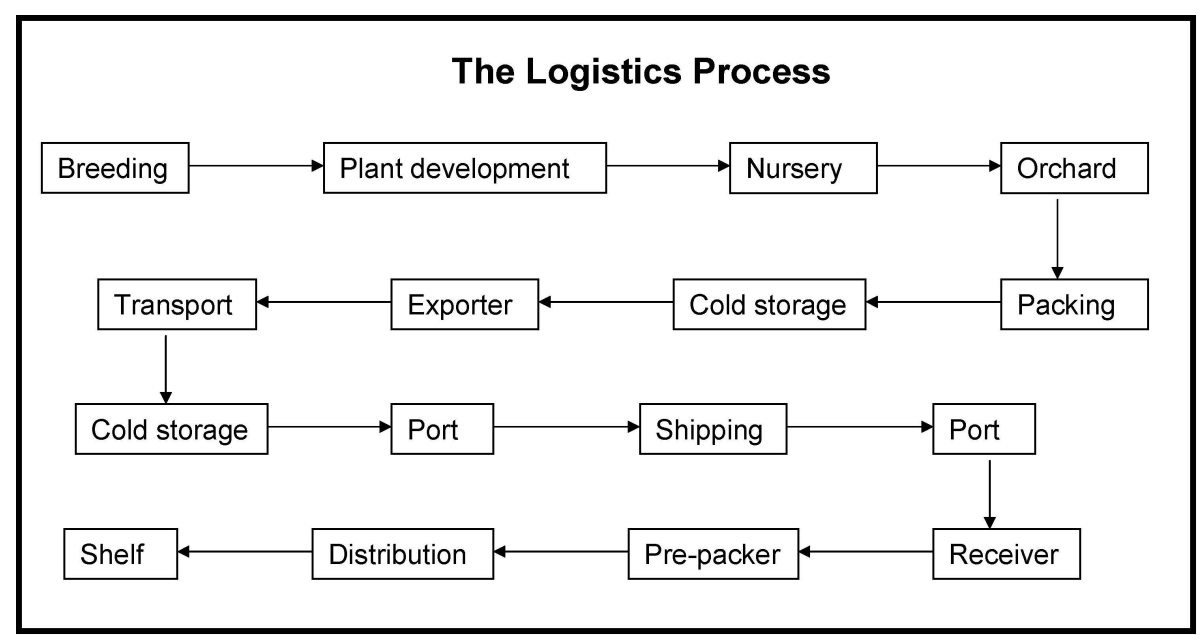

Figure 3: The fresh fruit export supply chain.

Prior to deregulation in 1997, the fresh fruit industry was regulated with one exporter each for citrus and deciduous fruit. Since then much has changed: the competition and complexity in the SA fresh fruit Industry have increased dramatically (with many more exporters and brands entering the industry) and prices have dropped. Producers were ill prepared for operating in the new deregulated environment due to no prior experience in such a market. Many fruit farms have been liquidated and exporters have disappeared as fast as they had appeared. This fragmentation of the industry has also led to increased pressure being placed on all facilities in the logistics chain. In 2003 there were approximately 70 accredited and registered exporters, with another estimated 216 producer/exporters (farmers who export fruit through private contract directly to an overseas retailer/client) giving a total of 386 enterprises engaged in the export of fresh fruit from South Africa [23].

In the same year there were some 420 pack houses and 300 registered cold stores in South Africa through which fresh produce is packaged, palletised and cooled to the required temperature. To ensure optimal quality of the fresh produce in the foreign market, strict temperature regimes/protocols (also known as Time Temperature Tolerances - TTT) have been developed for each fruit type by the national inspecting body; the Perishable Products Export Control Board (PPECB) and must be adhered to. For example, table grapes must be cooled to $-0.5{ }^{\circ} \mathrm{C}$ and maintained at that temperature throughout transport, storage and shipping. These requirements and other food safety regulations contribute to the complexity of the fruit export supply chain [25].

In the "Fruitful study" on the cold fruit supply chain between South Africa and the Netherlands [2] various logistics infrastructure capacity problems were identified, such as insufficient cold storage facilities in certain regions, not enough refrigerated vehicles suitable for fruit transport and bottlenecks in the fruit terminals. During the 2003/2004 season the peak export volume for deciduous fruit handled by the fruit terminals, shipping 
lines and other logistics service providers was approximately 6 million cartons in week 7 ( $2^{\text {nd }}$ week of February). The 2003/2004 deciduous export crop is expected to reach approximately 93 million cartons, compared to the 90 million cartons for the 2002/2003 season and the 75 million cartons in the 2000/2001 season. This growth in export volumes increases the pressure on the logistics infrastructure as more products require handling $[18]$.

The 2001 Trade and Industry South Africa (TISA) National Supply Chain Strategy Study [24] considers physical and technology infrastructure one of the essential elements required by an industry (sector) for gaining a competitive advantage. Related to this are the services that are provided on this infrastructure, which have a direct impact on the export competitiveness of the industry. The TISA study identified, amongst others:

- operational inefficiencies at ports,

- high inland transportation costs,

- the security and reliability of rail, and

- lacking rail facilities at ports

as drivers of increased supply chain costs and lead times. At industry level they recommend investigating collaboration around cold storage facilities at ports, logistics collaboration and sharing of facilities. In his 2002 State of the Nation address, the President made specific references to improving South Africa's competitiveness and efficiency. He said improving competitiveness requires "... lower input costs ...", “.. more efficient port operations ..." and other infrastructural efficiency improvements [19].

The National Ports Authority has recently expressed its concern about the congestion in the port of Cape Town as follows [14]: "The congestion in the Cape Town Container Terminal (CTCT) is a point of concern for all our customers. Delays caused as a result thereof have widespread consequences for all port users. The CTCT is presently experiencing unprecedented growth in volumes. This combined with present infrastructure layout, has led to a situation where the CTCT finds itself at the limit of its design capacity."

The consequences of a delay somewhere in the supply chain can be severe as it has a ripple effect throughout the whole supply chain. If a fruit batch misses a vessel and is held back for transportation on the next vessel, it might no longer match the market requirements or the market might be flooded in a particular week. If the market is put under undue stress, the price drops and normally does not recover for the rest of the season. For example, if the price of a carton of export grapes drops with 1 Euro early in the season, it can mean a loss of more than R300 million in income for the table grape industry alone (based on an exchange rate of approximately R9 to a Euro) [18].

It is further estimated that each $10 \%$ decrease in the export value for deciduous fruit (due to a drop in volume and/or price) will result in a loss of 75500 jobs, based on the economic multiplier effect described previously. Similarly, there will be a loss of R1 140 million to the economy and the government will loose R195 million in revenue [18]. 
Given the increasing production volumes, development of new markets and the shortage of logistics infrastructure capacity during peak seasons, the SA fruit industry identified the need to investigate the optimal usage of existing infrastructure on a national level and to make recommendations with regards to the development of additional infrastructure and the use of, for example, rail and alternative ports.

\section{Approach of the study}

The national fruit logistics infrastructure study comprised four phases.

\subsection{Phase 1}

The primary objective of phase 1 was to promote effective and efficient logistics operating practices amongst all the role-players in the fresh fruit supply chain. The lack of accurate and timely information exchange had previously been identified [2] as a shortcoming in the fresh fruit supply chain, resulting in bottlenecks and costly delays.

The first phase therefore entailed the development of a Supply Chain Information and Communication Procedure (ICP) [4], which contains a code of best practice for information sharing amongst the role-players in the fruit export supply chain. The ICP was initially developed for the table grape supply chain and was subsequently adapted for pome [5] and stone [6] fruit. Positive feedback has been received from the fruit industry emphasising that the development of an ICP has been long overdue. It is envisaged that compliance with the ICP will become part of the criteria for accreditation of exporters and service providers.

The table grape ICP was summarised on a poster, for display in pack houses, cold stores, service provider's offices, etc. The benefits of the ICP are perceived to be:

- More timeous and accurate information, which will enable

- Improved planning and management of operations, which will

- Reduce delays and bottlenecks, which will lead to

- Cost savings and longer shelf-life of the fruit.

\subsection{Phase 2}

The SA fruit industry did not have consolidated datasets of industry information such as contact details and capacities of pack houses and cold stores. Therefore these data had to be collected every time a study was undertaken in the fruit industry. Some of the information, such as production volumes, are available from the relevant producer organisation, but much can only be obtained from the individual facilities, such as cold store capacities.

An extensive data gathering exercise was therefore undertaken in the second phase to determine, amongst others, infrastructure capacities, production volumes and various costs. 
In spite of difficulties that were encountered during the data gathering process, due to the number of pack houses and cold stores, a lack of accurate data and a lack of cooperation from some of the industry role-players, a significant amount of data was collected. GIS maps were produced of the geographical spread and areas under cultivation for deciduous fruit. Maps were also produced of the flows of fruit from production regions to the ports during the 2003 season. In addition, a report containing a national and international overview of citrus, deciduous and subtropical fruit was compiled.

\subsection{Phase 3}

During phase 3 various studies were undertaken, mostly utilising masters or final year students from participating departments at the University of Stellenbosch, thereby capacity building students for entry into the fruit industry. Most of these departments had not previously been exposed to the fruit industry. The students were guided by their supervisors and the CSIR. The following studies were undertaken:

- A transaction cost analysis of the grape and citrus export supply chains to determine whether these costs could be reduced. A case study approach was followed. The study was completed by a Masters student at the Department of Agricultural Economics, University of Stellenbosch [10].

- A methodology for medium and long-term crop estimates was developed in order to improve the accuracy of these estimates. The study was conducted by OABS [13].

- Simulation models were developed for Fresh Produce Terminals in the Cape Town [12] and Durban [17] ports to analyse these terminals in more detail. Both simulation models were built by final year Industrial Engineering students from the University of Stellenbosch and are described in more detail in a subsequent paper [1].

- A maximum flow optimization model of the infrastructure network was developed to determine the maximum volume of produce that can be handled by certain sections of the network. The study was conducted by a masters student at the Department of Applied Mathematics, University of Stellenbosch [20,21] and is described in more detail in a subsequent paper [22].

- The use of road versus rail, alternative ports not currently used and the long-term development plans of the various SA ports were investigated. These studies were conducted by staff and students at the Department of Logistics, University of Stellenbosch $[11,15,16]$.

These studies provided valuable input for phase 4 .

\subsection{Phase 4}

In phase 4, the South African fruit production and export volumes were forecast for 2010 and various scenarios were analysed in order to determine whether investment in logistics infrastructure will be required in the foreseeable future. This included analyses of the fruit export volumes on the major roads and through the ports [26]. 
The road volumes were analysed by converting the estimated volume of fruit during a peak week on a particular road to an equivalent number of transport vehicles. The number of fruit vehicles was then compared with traffic count on the road. This was done for fruit transported on the N1, N2 and N7 to the port of Cape Town and for fruit transported on the N3 to the port of Durban. The annual tonnage of fruit as a percentage of total freight transported between the Western Cape and Gauteng, the Northern Cape and the Eastern Cape respectively, was also calculated. The rail volumes were not analysed as these volumes are known.

A Microsoft Excel model [27] was developed to determine the current and potential future utilisation of the various conventional and container terminals that load fruit for export. The model consists of a number of linked sheets, containing calculations of the

- production and export forecasts per fruit type (table grapes, pome fruit, stone fruit, hard citrus, soft citrus and subtropical fruit);

- fruit volumes exported through each port (Cape Town, Port Elizabeth, Durban and Maputo) per production region and fruit type;

- maximum weekly loading capacity in each of the terminals, and

- weekly utilisation of the conventional and container terminals.

The Excel model has been made available to the fruit industry. Industry role-players can easily change some of the data, parameters and/or assumptions to perform their own "what-if" analyses.

\section{$5 \quad$ Key findings}

A number of the key finding from the various project phases are noted in this section.

\subsection{Fruit export volumes on roads}

The analysis of the fruit export volumes transported on the main routes (N1, N2, N3 and N7) showed that, except on the N7, vehicles transporting fruit to the ports make a negligible contribution to the total number of vehicles per hour and the annual freight tonnage moved. Fruit currently represents $0.75 \%$ of the annual tonnage moved on the roads in the greater Boland area, and is forecast to be approximately the same in 2010. Presently less than $2 \%$ of the total annual freight tonnage that is transported on an interregional basis into the Western Cape represents fruit exports, except on the N7 where it represents $8 \%$. By 2010, this figure is not expected to change significantly except for the N7 where it could grow to $16 \%$.

Considering the number of fruit vehicles using the N1, N2 and N7 to go to the port of Cape Town and those using the N3 to go to the port of Durban during a peak week, the picture is much the same. In the worst-case scenario of spreading the fruit vehicles over only 7 of the 14 daylight hours, the number of fruit vehicles per hour represents $3 \%$ 
or less of the number of vehicles on the road, except on the N7 where the fruit vehicles represent $61 \%$ of the traffic. It is therefore understandable that the table grape industry is concerned about their contribution to traffic on the N7. However, it must be kept in mind that the total volume of traffic is still very low on the N7 and that the peak season lasts less than 3 months $^{2}$. The future utilisation of road capacity will mostly depend on the volume growth of "other" (non-fruit related) traffic [26].

\subsection{Fruit export volumes through ports}

As previously mentioned, fresh produce can bet exported through ports via either the conventional terminals (in pallets) in refrigerated vessels or through container terminals in refrigerated containers. Once fruit is delivered to the port, by road or rail, it is transported either directly to the quayside for immediate loading or to the stacks (containers) or terminal cold stores (pallets), for temporary storage until loading. The fruit is loaded onto vessels by gantry cranes (quayside cranes) or ships' gear (cranes on board the vessel). The analysis of the quayside capacity showed that there is sufficient capacity in all the conventional terminals for the (2010) forecasted volumes. However, the continuous supply of the required fruit to the quayside needs urgent attention. This will require upgrading some of the cold stores and the installation of IT infrastructure and software for the cold stores as well as for the transport management system.

The graphs in Figures 4 and 5 show the capacity utilisation over the whole year for the most important scenarios analysed for the conventional terminals in Cape Town and Durban respectively. The values in brackets in the legend for Figure 4, for example (447.4), indicate that the corresponding utilisation rate is for 4 berths and $47.4 \%$ of the fruit exported through the conventional terminals. The legend for Figure 5 includes a third value (for example, 3500), which indicates the average number of pallets that is loaded into the vessel. The number of pallets was not varied for the Cape Town analysis as the vessels are fully loaded there. However, in Durban the vessels are often only partly loaded.

All types of fruit are exported through the port of Cape Town. Therefore the conventional terminals are used almost year round, except for a very short period (approximately weeks 43 to 45 during 2003) when there is no fruit, as may be seen in Figure 4. Mainly citrus fruit is exported through the port of Durban. Therefore the conventional terminals are only used during the citrus season (approximately weeks 12 to 43 during 2003), as may be seen in Figure 5.

The Cape Town and Durban container terminals are operating at very high utilisation rates, which result in bottlenecks and delays. However, these terminals are being expanded at present and will have sufficient capacity for the (2010) forecasted volumes. The analysis showed that until the extra gantry cranes have been obtained in these terminals (hopefully before the end of 2005) the only short-term solution would be to increase the gantry crane loading rate from 17 to 20 moves per hour.

\footnotetext{
${ }^{2}$ According to 2004 data obtained from the Provincial Administration of the Western Cape, the average annual daily traffic (AADT) at Piekenierskloof is 2811 vehicles compared with a road capacity (rural AADT at capacity) of 4867 vehicles. Piekenierskloof is the section of the N7 that has the lowest capacity.
} 


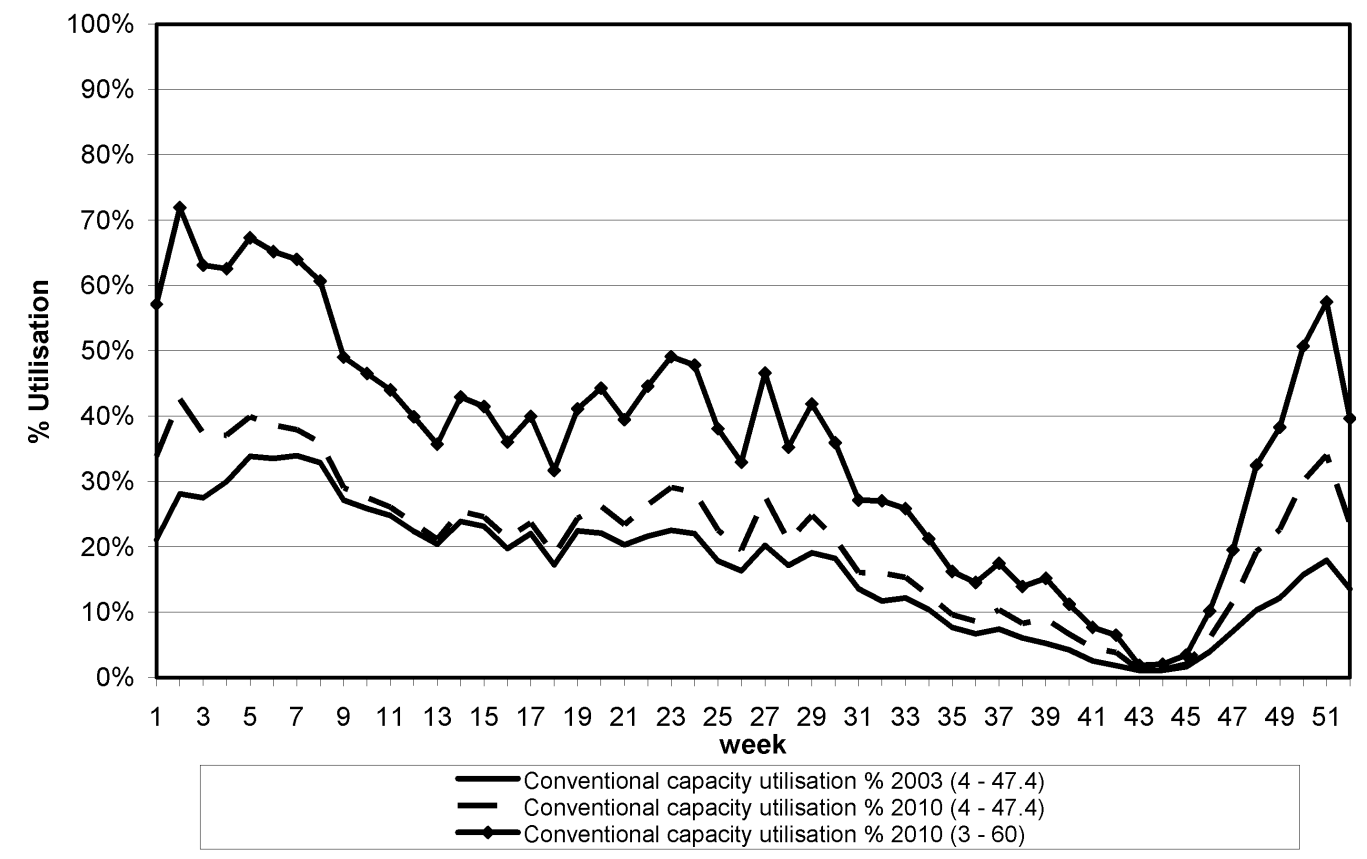

Figure 4: Cape Town conventional terminals utilisation.

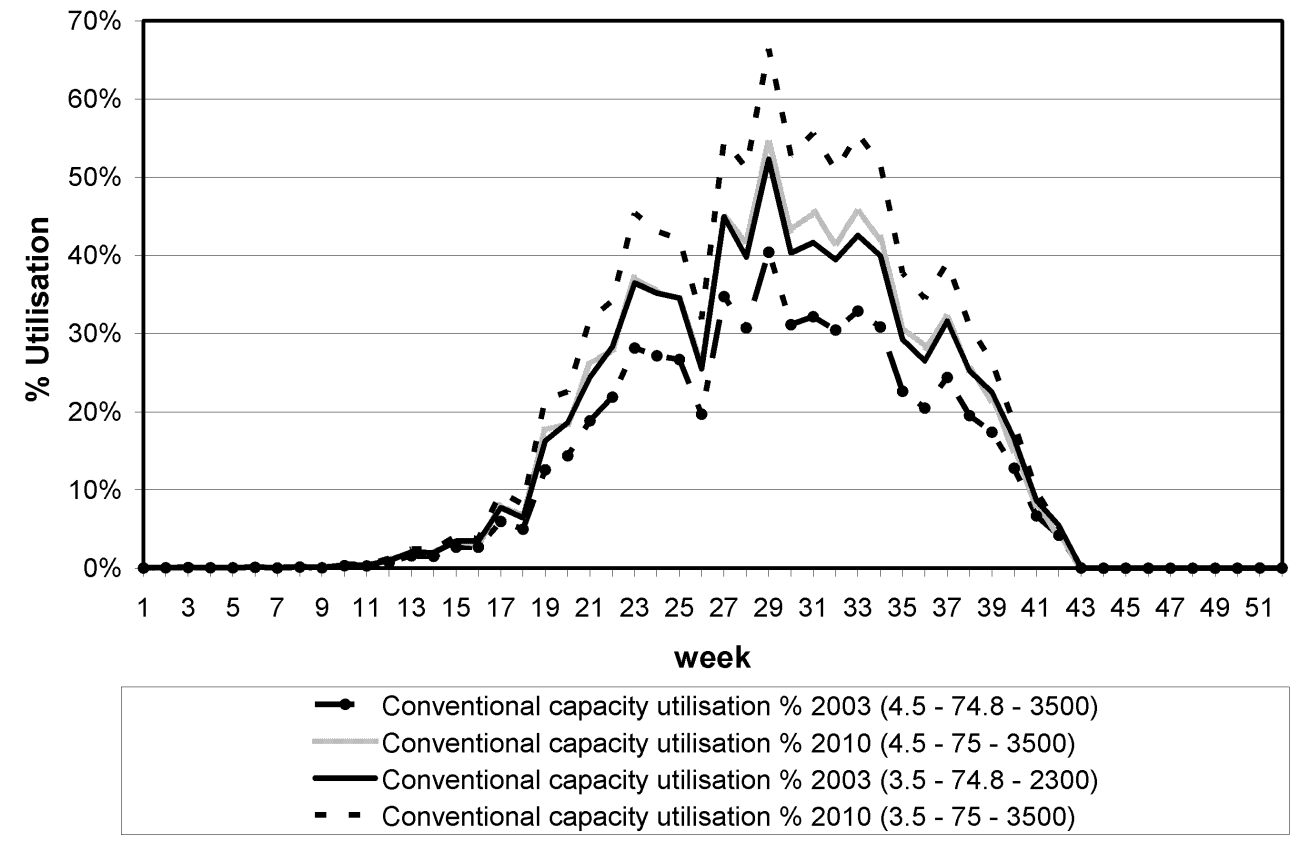

Figure 5: Durban conventional terminals utilisation. 
The graph in Figure 6 shows the reefer capacity and terminal capacity utilisation rates over the whole year for the most important scenarios analysed for the Cape Town container terminal. The values in brackets in the legend, for example (7@17), indicate that the corresponding utilisation rate is for 7 gantry cranes working at 17 moves per hour. The graph clearly shows the significant drop in overall terminal capacity utilisation rate that can be achieved by adding one gantry crane and increasing the loading rate by a few moves per hour. Note that since the number of plug points was more limiting than the loading rate in 2003, no improvement in the reefer capacity utilisation was achieved by an increase in the number of cranes and loading rate. The reefer capacity utilisation curve for 5 gantry cranes working at 17 moves per hour is therefore the same as the curve for 6 gantry cranes working at 20 moves per hour.

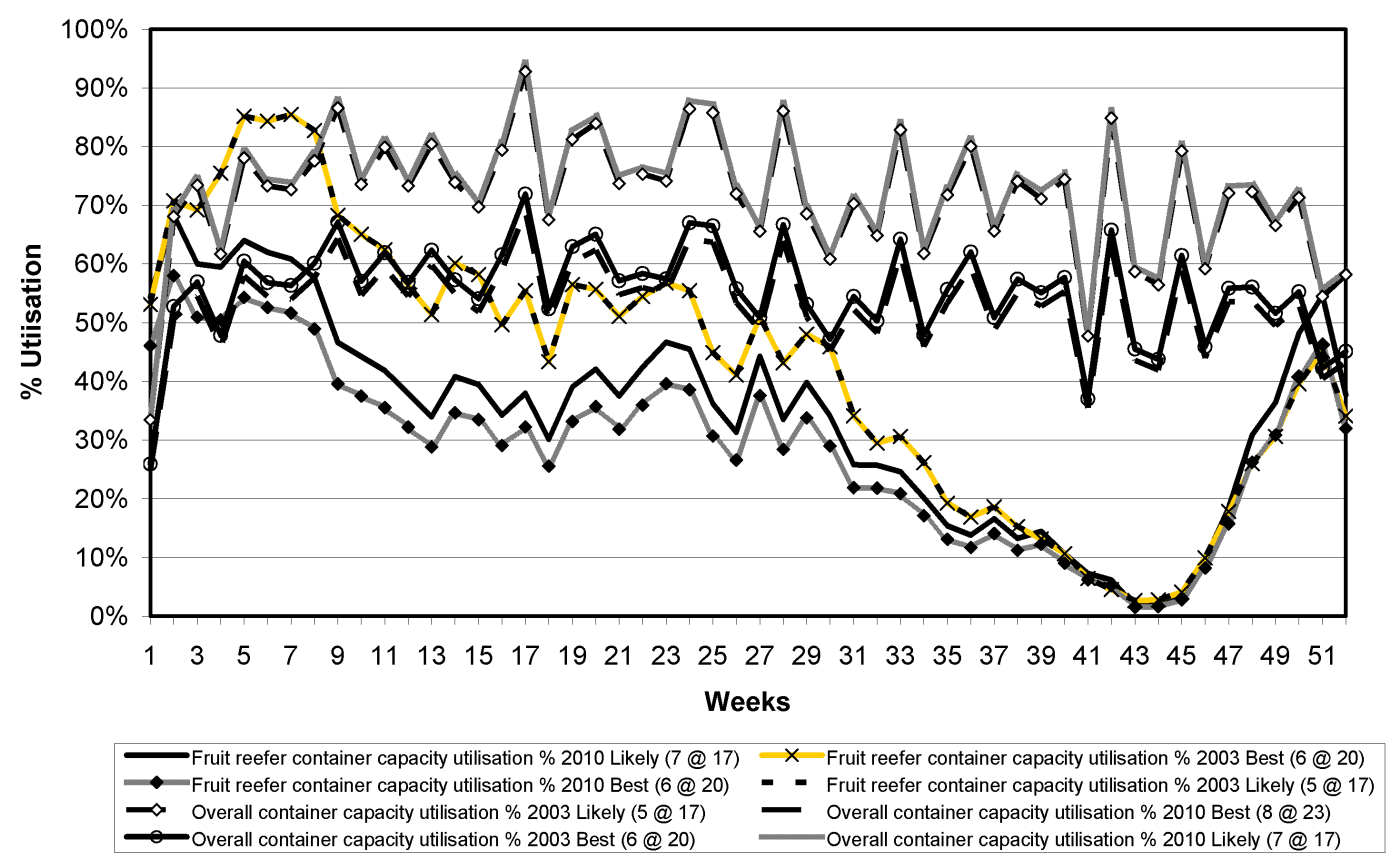

Figure 6: Cape Town container terminal utilisation.

The graph in Figure 7 shows the reefer capacity and terminal capacity utilisation rates over the whole year for the most important scenarios analysed for the Durban container terminal. Again the reefer capacity utilisation does not change with an increase in the number of gantry cranes or the loading rate, as it is limited by the number of plug points. This does not mean that the capacity is not sufficient, as can be seen from the curve for 2010 that peaks at $66.7 \%$, but quickly falls off to $55 \%$ and less.

As the utilisation rate of the terminals in Port Elizabeth and Maputo are much lower than the terminals in Cape Town and Durban, they are not discussed here. 


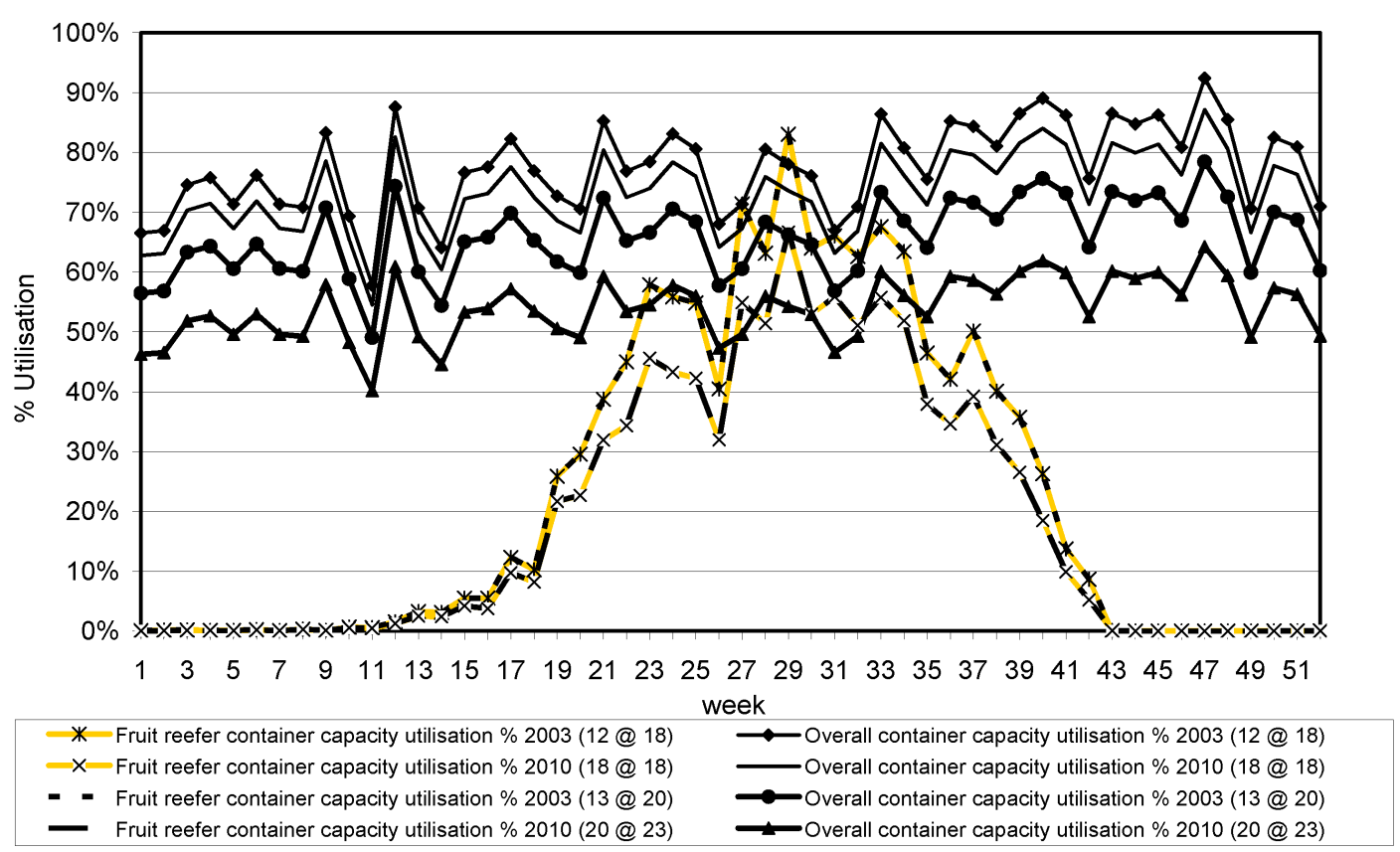

Figure 7: Durban container terminal utilisation.

\subsection{Capacity-limiting factors}

The analysis of the quayside capacity in the terminals was based on the assumption that enough vessels are available and that the cranes do not have to wait for fruit to be brought to the quayside for loading. Other capacity-limiting factors, which include the availability of vessels and integral reefer containers, stopping in more than one port to fill up a vessel, the cold sterilisation requirements for fruit exported to the Far East and the USA, and the availability of suitable cold-storage facilities in the vicinity of the ports, are discussed below.

During the past five to six years there has been a substantial increase in the volume of fruit exported in integral reefer containers. Internationally, approximately $60 \%$ of all fresh fruit is exported in reefer containers compared with approximately $40 \%$ in South Africa. It should be kept in mind that the newer specialised reefer vessels (conventional vessels) can carry up to 200 integral reefer containers on deck, which means that integral reefer containers do not necessarily have to be exported through a container terminal. It is not clear whether the percentage of fruit exported in containers will continue to increase in South Africa or how it will change in future, which makes it difficult to forecast whether enough vessels of the right kind will be available. The availability of vessels and integral reefers to the South African fruit industry is a function of worldwide demand and the revenue earned on other routes.

The current practice of loading a specialised reefer vessel in two (or sometimes more) ports, that is partly loading it in the first port and then filling it up in the second port, has a negative impact on the utilisation of the terminals and increases the cost substantially. This happens due to individual shipping lines not having enough cargo from their clients 
to fill an entire vessel in a single port. Some of the shipping lines are already addressing this problem by sharing loads such that vessels can be fully loaded in one port. When, for example, five vessels per week service approximately the same route to Europe during the peak of the citrus season, exporter and shipping lines should be encouraged to consolidate loads to fill vessels in a single port as far as possible.

The cold sterilisation requirements for fruit exported to the Far East and the USA are putting the quayside cold-store facilities under pressure. Also, one berth is typically dedicated to vessels loading this fruit. This reduces the capacity that is available for loading fruit destined for other markets.

The capacity and suitability of cold-storage facilities in the greater Durban area have been a problem for a number of years. The cold stores were designed, before deregulation, for the need of the single-exporter system, namely large volumes of identical pallets (same brand and packaging). This makes it difficult to cope with the needs of the large number of exporters who have numerous brands and different cartons to satisfy the ever-increasing demands of retailers and other clients. During the peak season some of the cold stores are not always able to load the vehicles within the time frame and in the sequence required to supply the conventional terminals with a continuous supply of the right fruit for a particular vessel, hatch and deck at the time needed, resulting in delays in vessel loading. This contributed $53 \%$ of the total delays experienced at FPT in Durban during the 2003 citrus season. The fruit industry has started to address this problem by creating a new cold store with random access storage and installing warehouse management software in some of the largest cold stores, which will help them to identify the location of the required pallets during order picking more quickly. However, this is probably still the single most critical logistics bottleneck in the fruit export supply chain and requires urgent attention as it costs the industry dearly.

One of the most limiting factors with respect to the capacity of any facility in any supply chain, is undoubtedly labour. An efficient, well-trained and motivated workforce is required for the successful operation of any cold store or terminal. It cannot be overemphasised that the human factor often determines the success or failure of an operation. It is therefore imperative to equip labour with the tools they require to perform their duties successfully. These tools may be physical, such as best-quality equipment, protective gear, etc., or more intangible such as adequate training, incentive schemes and supply-chain education to the point where the worker understands the part that he/she plays in the entire supply chain. The potential restructuring of the ports system in South Africa, with the concessioning of certain terminals and the expansion of key ports, will have an effect on labour, especially with regards to stevedoring gangs, crane operators and terminal personnel working inside the port boundaries.

\section{Recommendations}

The following recommendations were made to the fruit industry with regard to aspects that need attention or warrant further investigation [3]:

- Analyse and address the factors affecting the continuous supply of the right fruit at 
the right time from the cold stores to the quayside, especially in the greater Durban area before the 2004 citrus peak (see $§ 5.2$ ).

- Continue to lobby, in collaboration with other export industries to address the productivity and labour issues at container terminals urgently (see §5.2).

- Encourage shipping lines and exporters to consolidate loads to fill vessels in a single port (see $\S 5.3)$.

- Investigate the future demand for specialised reefer (conventional) vessels, container vessels and integral reefer containers (see $§ 5.3$ ).

- Develop a mechanism to divert fresh produce from traditional export ports to those ports where surplus capacity exists, should the need arise to relieve congestion at a particular port. (It is unlikely that an exporter will voluntarily divert his/her fruit to another port to relieve congestion as the land transport cost will most probably be higher.)

- Assess the viability of diverting more of the citrus exports from Durban to Maputo as

- Maputo is the closest port to Mpumalanga, Limpopo and Swaziland,

- Extensive rehabilitation is taking place at Maputo port,

- There is a conventional fruit terminal in the port, and

- There has been increased effort to stimulate the Maputo Corridor.

- Assess the economic viability of Lüderitz as an alternative port for the export of fresh produce from South Africa and Namibia.

- Conduct a cost-benefit analysis of the use of rail to transport fresh produce from production regions to ports. One example could be a year-round regular container train service carrying reefer and non-reefer containers between the Orange River area and Cape Town.

- Engage in discussion with other industries that are sharing the same road infrastructure to find joint solutions for transforming some of the freight volumes off roads.

- Invest in logistics and supply-chain awareness and management training in all links of the fruit export supply chain.

It is the opinion of the authors that although logistics infrastructure provides some challenges, information sharing, collaborative planning and productivity will be the deciding factors between failure and success in getting the fruit to foreign markets without delay and in good condition. 


\section{Conclusions}

This paper gave an overview of a study that was done on the logistics infrastructure used by the South African fruit industry. The aim of the study was to promote effective and efficient logistics operations amongst all the role-players in the fresh fruit supply chain, and to make recommendations for the utilisation of, and investment in, logistics infrastructure in order to enhance the competitiveness of the SA fruit industry.

There was much interest in the study and its findings from the fruit industry. It was described by role-players as long overdue, relevant and important for future sector growth. Throughout the course of the study substantial insight into the inner workings of the fruit industry and its possible future was gained by the many role-players who were actively involved in the study. The publishing of the various reports and the Excel model on the website of the Deciduous Fruit Producers' Trust was particularly well received as the results of the study are easily accessible by all role-players and became "industry owned." The fruit industry and funding partners were satisfied that the aims of the study had been met.

\section{References}

[1] Bekker JF, Mostert M, \& VAN Dyk FE, Simulation of fruit pallet movement in the port of Durban, submitted.

[2] Broens DF, Van Dyk FE \& Tavasszy LA, 2000, The cold fruit supply chain between South Africa and the Netherlands, TNO Report, Delft.

[3] CSIR - Transportek, 2004, Brief terms of reference for further investigation, [Online], [Cited October 8th, 2004], Available from http:// www.dfpt.co.za/fruitlog/Phase\%204/Future\%20T0Rs\%20March\%202004.pdf

[4] CSIR - Transportek, 2003, Grape supply chain information and communication procedure, [Online], [Cited October 8th, 2004], Available from http://www.dfpt.co.za/ fruitlog/Phase\%201/Grape\%20ICP-\%202003.pdf

[5] CSIR - Transportek, 2003, Pome fruit supply chain information and communication procedure, [Online], [Cited October 8th, 2004], Available from http:// www.dfpt.co.za/fruitlog/Phase\%202b/Pome\%20ICP\%20Final\%202003.pdf

[6] CSIR - Transportek, 2003, Stone fruit supply chain information and communication procedure, [Online], [Cited October 8th, 2004], Available from http://www.dfpt.co.za/ fruitlog/Phase\%202b/Stone\%20ICP\%20-\%202003.pdf

[7] Eckert JB, Liebenberg GF \& Troskie DP, 1997, Commercial agriculture in the Western Cape: Macroeconomic analysis with a social accounting matrix, Agrekon, 36(3), pp. 302-324.

[8] Fruit South Africa, 2004, Fresh fruit exports from South Africa handbook, Cape Town. 
[9] Fruit South Africa, 2003, The trade chain of the South African fresh fruit export industry - consumer demand (Book 6 of 9), Cape Town.

[10] Fundira T., 2003, A transaction cost analysis of the fruit supply chain in South Africa: A case study approach, MAgric Admin Mini-thesis, University of Stellenbosch, Stellenbosch.

[11] Goedhals LL, 2003, Fruit export from South Africa after deregulation - changes required to the infrastructure and supply chain, MEcon Mini-thesis, University of Stellenbosch, Stellenbosch.

[12] Kritzinger CC, 2003, Simulation model of FPT - Cape Town, BEng (Industrial) Final Year Project, University of Stellenbosch, Stellenbosch.

[13] Louw D \& Fourie M, 2003, Crop estimate methodology for fruit, [Online], [Cited October 8th, 2004], Available from http://www.dfpt.co.za/ fruitlog/Phase $\% 203 \% 20$ reports/Crop\%20estimate\%20methodology.pdf

[14] Louw D \& Hoffman D, 2002, Looming threat for fruit logistics?, South African Fruit Journal, 1(2), pp. 63-70.

[15] Louw NH, 2003, Luderitz as moontlike uitvoerhawe vir vrugte, [Online], [Cited October 8th, 2004], Available from http://www.dfpt.co.za/fruitlog/ Phase $\% 203 \% 20$ reports/Luderitz.doc.pdf

[16] Marx M, Pienaar D \& Brotherton M, 2003, Road vs. rail: Grape transportation, BComm(Hons) Seminar, University of Stellenbosch, Stellenbosch.

[17] Mostert M, 2003, The development of a computer simulation model of the Durban fresh produce terminal, BEng (Industrial) Final Year Project, University of Stellenbosch, Stellenbosch.

[18] Louw D, 2004, Optimal Agricultural Business Systems, Personal communication.

[19] Office of the President, 2002, State of the nation address by the president of South Africa, Thabo Mbeki, to the joint sitting of the houses of parliament, [Online], [Cited October 8th, 2004], Available from http:// www. southafrica-newyork.net/consulate/speeches/sna2002.htm

[20] Ortmann FG, 2003, Modelling the South African fruit export infrastructure: Determining the maximum flow volume, [Online], [Cited October 8th, 2004], Available from http://www.dfpt.co.za/fruitlog/Phase\%203\%20reports/ Optimization\%20model\%20results.pdf

[21] Ortmann FG, 2003, Modelling the south african fruit export infrastructure: Model development and user guide, [Online], [Cited October 8th, 2004], Available from http://www.dfpt.co.za/fruitlog/Phase $\% 203 \% 20$ reports/ Optimisation $\% 20$ model $\% 20$ report.pdf

[22] Ortmann FG, Van Vuuren JH \& Van Dyk FE, Modelling the South African fruit export infrastructure, submitted. 
[23] Gibson J, 2004, Perishable Products Export Control Board, Personal Communication.

[24] TISA, 2001, National supply chain strategy study, Pretoria (presentation slides).

[25] VAN DYK FE, 2003, Fruit industry datasets 83 maps (phase 2a), [Online], [Cited October 8th, 2004], Available from http://www.dfpt.co.za/fruitlog/phase $\% 202$ a/datasets $\% 20$ and $\% 20$ maps\%20report.pdf

[26] VAN DyK FE, 2004, Fruit logistics scenario analyses, [Online], [Cited October 8th, 2004], Available from http://www.dfpt.co.za/fruitlog/Phase $\% 204 /$ Fruit $\% 20$ Logistics $\% 20$ Scenario\%20Analysis\%20March2004.pdf

[27] VAN DYK FE, 2004, Fruit logistics scenario model, [Online], [Cited October 8th, 2004], Available from http://www.dfpt.co.za/fruitlog/Phase\%204/ FruitLog\%20Scenario\%20Model.xls

[28] VAN DYK FE, 2004, Fruit logistics scenario model, [Online], [Cited October 8th, 2004], Available from http://www.dfpt.co.za/fruitlog/ Phase $\% 204 /$ FruitLog $\% 20$ Scenario\%20Model.xls 